\title{
ARTIGOS
}

\section{ASSOCIAÇÃO ENTRE GLIOXALASE I E PARACOCCIDIOIDOMICOSE-INFECCÃO}

\author{
Marly A.S. Balarin e Dértia Villalba Freire-Maia
}

\begin{abstract}
Com o objetivo de se estudar a susceptibilidade genética à paracoccidioidomicoseinfecção, procurou-se determinar uma possivel associação entre a glioxalase la e a reação intradérmica à paracoccidioidina. O fenótipo GLO 1 ocorreu em freqüência significctivamente mais alta entre os indivíduos com reação positiva.
\end{abstract}

Palavras-chaves: Glioxalase I. Paracoccidioidomicose. Paracoccidioidina. Genética. Micoses.

A glioxalase I (GLO I) é um marcador genético cujo gene está localizado no braço curto do cromossomo 6 humano e está em equilíbrio de ligação com o sistema HLA 781420 . Há dois alelos autossômicos codominantes $G L O^{1}$ e $G L O^{2}$ originando três fenótipos: GLO 1, GLO 2-1, GLO 2. O polimorfismo da glioxalase I foi descrito por Kompf e cols?.

A paracoccidioidomicose, micose sistêmica causada pelo fungo Paracoccidioides brasiliensis, apresenta diversas manifestações clínicas e patológicas, além de uma variedade de formas clínicas. A infecção humana é adquirida principalmente por inalação dos esporos de $\boldsymbol{P}$. brasiliensis, o qual vive saprofiticamente na natureza11. Ao entrar em contato com o fungo, uma pessoa pode desenvolver a paracoccidioidomicose-doença ou a paracoccidioidomicose-infecção, dependendo da ação de diversos fatores ${ }^{1}{ }^{19}$. A paracoccidioidomicose-infecção pode ser identificada através da reação intradérmica à paracoccidioidina (RIP).

A resistência à infecção pelo $P$. brasiliensis foi descrita em ratos como sendo controlada por um único gene autossômico dominante 2 .

Na tentativa de se verificar se fatores genéticos influenciam na resistência do ser humano à infecção

\footnotetext{
Departamentos de Ciências Biológicas da Faculdade de Medicina do Triângulo Mineiro, Uberaba, MG e de Genética, Instituto de Biociências da Universidade Estachual Paulista, Botucatu, SP.

Suporte financeiro - FAPESP.

Endereço para correspondência: Dra. Marly A. Spadotto Balarin. Genética/Depto. de Ciências Biológicas/FMTM. Praça Manoel Terra s/n, 38015-050 Uberaba, MG, Brasil.

Recebido para publicação em 30/04/93.
}

pelo $P$. brasiliensis, alguns trac ${ }^{2}$ hos foram realizados com marcadores genéticos, comognepos sanguíneos $\mathrm{ABO}$ e antígeno leucocitário humano (HLA), em indivíduos com paracoccidioidomicose-doença, porém os resultados são contraditórios 561213161718 . Em relação à paracoccidioidomicose-infecção, nenhuma referência bibliográfica foi encontrada.

Com o objetivo de estudar a susceptibilidade à paracoccidioidomicose-infeç̧ão procurou-se no presente trabalho determinar se há associação entre a glioxalase I e o teste intradérmico à paracoccidioidina.

\section{MATERIAL E MÉTODOS}

Foram coletadas amostras de sangue periférico de 223 indivíduos brancos, sendo 114 masculinos com idade média de $31,06 \pm 18,30$ anos e 109 femininos, com idade média de 29,50 $\pm 15,83$ anos, residentes em Pratânea-SP, considerada área endêmica de paracoccidioidomicose ${ }^{15}$.

Todos os indivíduos foram submetidos à reação intradérmica à paracoccidioidina, antígeno solúvel, polissacarídico, preparado de acordo com o método padronizado por Fava Netto e Rafael ${ }^{3}$. As reações com nódulo de enduração igual ou superior a $5 \mathrm{~mm}$ no seu diâmetro maior foram consideradas como positivas, e as outras, como negativas.

As hemácias, utilizadas para o estudo do polimorfismo enzimático da GLO I, foram lavadas três vezes em salina isotônica $(\mathrm{NaCl} 0,15 \mathrm{M})$, estocadas em glicerol tamponado a $-20^{\circ} \mathrm{C}$ e analisadas pelo método de Kuhnl e cols ${ }^{10}$ com modificações. Pouco antes do uso, foi preparado o hemolisado, sendo colocada na suspensão uma gota de água bidestilada gelada. Após agitação, a suspensão foi 
Balarin MAS, Freire-Maia DV. Associą̧üo entre glioxialase l e paracoccidioidumicose-infecção. Revista da Sociedade Brasileira de Medicina Tropicai 25:141-143, jul-set, 1993.

incubada a $4^{\circ} \mathrm{C}$ por 1 úmin. Apos a liemólise, fo ram adicionadas ao tubo duas gotas de tetracloreto de carbono. O material foi acitado 'ig, rosanente por um minuto, centrifigado a $1500 \mathrm{rpm}$ por $10 \mathrm{~min}$ e mantido a $4^{\circ} \mathrm{C}$ até o niotiento do uso.

Três microlitos do hemolisado foran aplicados utravés de papéis de filtro $2 \times 10 \mathrm{~mm}$, inseridos em pequenos cortes no gel de agarose (BKL - Funbec) a $0,8 \%$. de tampão Tris $0,1 \mathrm{M}$ (Sigına)/ácido cítrico $0,28 \mathrm{M}$ (Merck) $\mathrm{pH}$ 7,5, diluído 1:4. O gel foi colocado em câmara úmida a uma voltagem de $5,5 \mathrm{v} / \mathrm{cm}$, por 2 horas e $30 \mathrm{~min}$ a $4^{\circ} \mathrm{C}$.

Na parte anódica do gel foi colocaoo un papel de filtro com solução de $40 \mathrm{mg}$ de glutation reduzido (Sigma) e $0,2 \mathrm{ml}$ de metil glioxal em tampão fosfato $0,2 \mathrm{M} \mathrm{pH} 6,7$. Após a incubação por 20 minutus a $37^{\circ} \mathrm{C}$, o gel foi corado com uma solução de $10 \mathrm{mg}$ MTT (azul de tiazolil - Sigma) e 0,5mg de DCIP (dicloro-fenolindofenol - la Motte) e 10ml je agar em tampão de Tris $0,1 \mathrm{M}$ pH 8,5.

Os controles foram constituídos por amostras de fenótipos conhecidos.

\section{RESULTADOS E DISCUSSÃO}

Os fenótipos GLO 1, 21 e 2 ocorreram, no total da amostra, com freqüências aproximadas de 18,54 e $28 \%$, respectivamente (Tabela 1). Como não foi encontrada diferença sexual estatisticamente significativa homens e mulheres foram agrupados, e a freqüência do gene $G L O^{1}$ é igual à encontrada por Franco e cols ${ }^{4}$ em indivíduos orancos da população de Porto Alegre $(0,45)$. Nenhum desvio significativo do equilíbrio de Hardy.Weinberg foi observado quando os fenótipos tiram analisados separadamente em cada sexo e no total.
No entanto, foram significativas as diferenças de freqüência do fenótipo de GLO 1 entre os RIP positivos e os negativos (Tabela 1), com um excesso de prevalência entre os primeiros. Com base nesses resultados, sugerimos uma hipótese de que haja associação entre a paracoccidioidomicose-infecção e o loco GLO 1.

\section{AGRADECIMENTOS}

Agradecemos ao Prof. Dr. Ademar FreireMaia pela revisão e sugestões dadas e a Cristine $P$. Nogueira pela orientação no estabelecimento da técnica.

\section{SUMMARY}

With the puipose to study the genetic susceptibility to paracoccidioidomycosis-infection we searched for a possible association between glyoxalase $I$ and the intradermic paracoccidioidin reaction. The phenotype GLO 1 was significantly more frequent among positive reactors.

Key-worts: Ghyoxalase I. Paracoccidioidomycosis. Paracoccidioidin. Genetic. Mycosis.

\section{REFERÊNCIAS BIBLIOGRÁFICAS}

1. Aibornoz MB. Paracoccidioidomicosis-infección. In: Del Negro G, Lacaz CS, Fiorillo AM (eds) Paracoccidioidomicose: blastomicose sul-americana $1^{\text {a. }}$ edição Savier, EDUSP, São Paulo p.1-9, 1982.

2. Calich VLG, Burger E, Kashino SS, Fazioli RA, Singer. Vermes LM. Kesistance to Paracoccidioides br usiliensis in mice is controlled by a single dominant autosomal gene. Iufection and Immunity 55:1919-

Tabela 1 - Distribuiçäo aú freqüênrịi dos fenótipos aa GLO I em relação à reação intradérmica a paracoccidividina ${ }_{i}$ KIr;

\begin{tabular}{|c|c|c|c|c|c|c|c|}
\hline \multirow[t]{3}{*}{ RIP } & & & \multicolumn{4}{|c|}{ Fenótipo GLO I } & Total \\
\hline & \multicolumn{2}{|c|}{1} & \multicolumn{2}{|c|}{$2-1$} & \multicolumn{2}{|c|}{2} & \\
\hline & $o^{(*)}$ & e & 0 & e & 0 & $\mathrm{e}$ & \\
\hline Positiva & 20 & 13,99 & 44 & 42,32 & 14 & 21,69 & 78 \\
\hline Negativa & 20 & 26.01 & 77 & 78,68 & 48 & 40,31 & 145 \\
\hline \multirow[t]{2}{*}{ Total } & (il) & & 121 & & 62 & & 223 \\
\hline & (\%) 18 & & 54 & & 28 & & \\
\hline
\end{tabular}


Balarin MAS, Freire-Maia DV. Associação entre glioxalase I e paracoccidioidomicose-infeç̧ão. Revista da Sociedade Brasileira de Medicina Tropical 26:141-143, jul-set, 1993.

1923, 1987.

3. Fava Netto C, Raphael A. A reação intradérmica com polissacáride do Paracoccidioides brasiliensis, na blastomicose sul-americana. Revista do Instituto de Medicina Tropical de São Paulo 3:161-165, 1961.

4. Franco MHLP, Moreira DM, Salzano FM, Santos SEB, Conceição MM, Schneider H. New data on the association between the glyoxalase Iand haptoglobin loci. Human Heredity 36:126-128, 1986.

5. Goldani LZ, Monteiro CMC, Donadi EA, Martinez R, Voltarelli JC. HLA antigens in Brazilian patients with paracoccidioidomycosis. Mycopathologia 114:89-91, 1991.

6. Gonzáles NM, Albornoz MB, Rios R, Prado L. Paracoccidioidomicosis y su relación com el sistema HLA. In: Anais do $2^{\circ}$. Encontro sobre Paracoccidioidomicose, Universidade Estadual Paulista "Júlio de Mesquita Filho", Botucatu, resumos adicionais, 1983.

7. Hansen HE, Eriksen B. HLA-GLO linkage analysis in 57 informative families. Human Heredity 29:355$360,1979$.

8. Hansen HE, Olesen Larsen $S$, Eriksen B. No linkage disequilibrium HLA-GLO found in 1.004 normal, unrelated danes. Human Heredity 31:15$18,1981$.

9. Kömpf J, Bissbort S, Gussmann S, Ritter H. Polymorphism of red cell glyoxalase I (E.C.: 4.4.1.5). A new genetic marker in man. Humangenetik 27:141143,1975 .

10. Kühnl P, Schwabenland R, Spielmann W. Investigations on the polymorphism of glyoxalase I (EC 4.4.1.5) in the population of Hessen, Germany. Human Genetics 38:99-106, 1977.

11. Lacaz CS, Zamith VA, Del Negro G, Siqueira AM. Aspectos clínicos gerais. Formas polares da paracoccidioidomicose. Particularidades clínicas infanto-juvenis. In: Del Negro G, Lacaz CS, Fiorillo AM (eds) Pa racoccidioidomicose: blastomicose sulamericana. $1^{\text {a. }}$ edição Sarvier, EDUSP, São Paulo p.141-147, 1982.
12. Lacerda GB, Arce-Gomez B. HLA e paracoccidioidomicose (PCM). Anais do $2^{0 .}$ Encontro sobre paracoccidioidomicose, Universidade Estadual Paulista "Júlio de Mesquita Filho", Botucatu p.9, 1993.

13. Lacerda GB, Arce-Gomez B, Queiroz Telles Filho $F$. Increased frequency of HLA-B40 in patients with paracoccidioidomycosis. Journal of Medical and Veterinary Mycology 26:253-256, 1988.

14. Leach $R$, Demars $R$, Hasstedt $S$, White $R$. Construction of a map of the short arm of human chromosome 6. Proceeding of the National Academy of Sciences of the United States of America 83:39093913, 1986.

15. Marques SA, Franco MF, Mendes RP, Silva NCA, Baccili C, Curcelli ED, Feracin ACM, Oliveira CS, Tagliarini JV, Dillon NL. Aspectos epidemiológicos da paracoccidioidomicose na área endêmica de Botucatu (São Paulo - Brasil). Revista do Instituto de Medicina Tropical de São Paulo 25:87-92, 1983.

16. Mendes RP, Colauto EMR, Meira DA, Barraviera B. Freqüência de sistemas sanguíneos em doentes com paracoccidioidomicose, da região de Botucatu. Anais do $2^{\circ}$. Encontro sobre Paracoccidioidomicose, Universidade Estadual Paulista "Júlio de Mesquita Filho", Botucatu p.8, 1983.

17. Ponsirenas CVG. Estudo de associação entre os antígenos HLA-A, B e Dr com as formas crônicas da paracoccidioidomicose. Tese de mestrado, Universidade Federal do Paraná, Curitiba, 1991.

18. Restrepo FM, Restrepo M, Restrepo A. Blood groups and HLA antigens in paracoccidioidomycosis. Sabourandia 21:35-39, 1983.

19. San-Blás G, San-Blás F. Paracoccidioides brasiliensis cell wall structure and virulence. Mycopathologia 62:77-86, 1977.

20. Wong P, Komarnicki L, Schroeder ML, Lewis M, Kaita H, Philipps S, Stranc L, McAlpine PJ. Analysis for linkage between F13A and three chromosome 6 marker loci: evidence for 6pter:F13A: HLA:GLO1:cen gene order. Human Genetics 79:228-230, 1988. 